\title{
Scope Interpretation of English Quantifiers: The Case of the Nigerian Second Language Learners
}

Isioma Maureen Obi, Stephen Anurudu*

English Studies Department, University of Port Harcourt, University of PMB 5323 Choba, East-West Rd, Port Harcourt, Nigeria

DOI: $10.36347 /$ sjahss.2020.v08i04.005

| Received: 30.03 .2020 | Accepted: 06.04.2020 | Published: 14.04.2020

*Corresponding author: Stephen Anurudu

Abstract

Original Research Article

The study of second language acquisition and problems surrounding this field has received attention from scholars in recent times. These studies have however paid less attention to the problem of quantification and interpretation of quantifier expressions by second language learners in Nigeria. As a result, this study adopts a truth-value judgment task and insights from Chomsky's principles and parameters approach to examine the interpretation of ambiguous quantifier expressions among Nigerian undergraduates. From our study, second language learners usually make preference for a narrow interpretation. This preference is as a result of lexical bias, structural position as well as the linguistic system of learners' first language. The right input from the second language, as our study revealed, can resolve issues emanating from these ambiguities. An understanding of the processing system of learner's L1 is necessary to reducing narrow interpretations and should be given proper attention by language scholars.

Keywords: Quantifiers, scope interpretation, language acquisition, input.

Copyright @ 2020: This is an open-access article distributed under the terms of the Creative Commons Attribution license which permits unrestricted use, distribution, and reproduction in any medium for non-commercial use (NonCommercial, or CC-BY-NC) provided the original author and source are credited.

\section{INTRODUCTION}

In Nigeria, there are over 400 indigenous languages. Despite the plethora of languages, English language plays a major role in the country; it serves as the official language and the language of instruction from primary to tertiary levels. Second language learners map grammatical patterns of their L1 into English resulting in poor syntactic structures and difficulty in disambiguation of sentences. A major area of concern is the interpretation of quantifier expressions. A quantifier is a type of determiner, such as all, some, many, few, a lot, less, and no, that indicates quantity [1]. Quantifiers state precisely or suggest approximately the amount or the number of a noun. The most obvious function of these expressions is to convey information about an amount or a proportion. When presented with quantified ambiguous sentences, learners attempt an isomorphic interpretation of quantified expressions creating a rather narrow understanding. This results in breach in communication as well as poor academic performance.

While studies have focused on quantifiers in general, only little attention has been paid to interpretation of scopally ambiguous quantified expressions by L2 English learners in Nigeria. This study therefore seeks to
- Examine the interpretive preferences of ambiguous quantifier expressions by L2 learners in Nigeria in order to examine whether these preferences are as a result of grammatical features of the L1.

- Examine the role of context in disambiguating quantified expressions.

The study further suggests ways that learners can improve on their understanding of English quantifiers and how teachers can aid the acquisition process thereby reducing sentence ambiguities.

\section{SCOPE OF QUANTIFIERS}

Scope refers to the term used to describe the relationships between operators such as quantifiers, negation or wh-expressions and other parts of a sentence [2]. When more than one quantifier is present in an expression, the scope of an expression shows the meaning relations between the component parts of a sentence [3]. This relationship is referred to as constituent command in syntax [3]. In interpreting sentences, the scope would cover the meaning restriction of a particular expression. The concept of scope is important in second language acquisition as it provides a framework for explaining ambiguities and accounting for operator relationships. Scope 
interactions account for how a sentence can be interpreted. Examining the interaction of two quantifiers 'every' and ' $a$ ' in the first construction and 'not' and 'all' in the sentence below

Every boy rode a bicycle.

$\forall \mathrm{x}[\operatorname{boy}(\mathrm{x})$ rode a bicycle $(\mathrm{x})]$

This sentence has two readings. First, it could mean that every boy is such that they rode a particular bicycle. A second reading could mean that every boy rode a different bicycle. In the first interpretation, a linear or narrow reading is such that the universal quantifier 'every' has scope over the object 'a bicycle'. i.e every boy rode a particular bicycle this is also known as a restricted set interpretation. In the second reading, an inverse or wide scope reading occurs such that the existential quantifier ' $a$ ' scopes over the universal quantifier 'every' to mean that for every boy, there was a different bicycle that they rode. We can also describe this as a complete set interpretation where the quantifier ' $a$ ' is raised beyond its NP.

All the students came to school.

$\forall \mathrm{x}$ [students(x) $\square$ came to school (x)]

There is no ambiguity in the sentence above. The expression implies that each student is a subset of the universal set 'all' [4] and so came to school. A second instance is the sentence below:

All the students did not come to school.

a. $\forall \mathrm{x}$ [student (x) $\square \neg$ came to school (x)] (= none of the students came to school)

b. $\neg \forall \mathrm{x}$ [students (x) $\square$ came to school (x)] (= not every student came to school)

The reading of the sentence above could mean that the entire members of the universal set (all the students) did not come to school (none of the students came). Here, the scope of 'not' is universal. In a second instance, the sentence could also mean that not all the students came to school; where the scope of the negative quantifier 'not' is restricted to a subset of the entire set (all the students).

Interpretation of scope has been a major concern for L2 learners. Different studies have emerged in this field to account for factors that enhance scope interpretations of ambiguous quantifier expressions. At a syntax and semantic interface earlier studies suggested that the thematic roles of individual quantifiers and syntactic position of quantifiers play a major role in individual's preferences [5]. Within the tenets of generative grammar, studies have shown that certain expressions are not processed in the L1 and therefore pose a problem to disambiguation of quantifiers. Chomsky's poverty of stimulus accounts for poor processing of quantifiers [6]. Contrary to the generativist approach, the emergentists argue that difficulty in interpreting scope ambiguous expressions are as a result of the economy of the working memory rather than parameters governing the language of the L1
$[7,8]$. Based on studies conducted, one would argue that interpretation of scope in a function of the learner's innate abilities rather than external influences.

The interpretive preferences in this study are accounted for within the framework of Chomky's Universal Grammar. The hypothesis is that 'all principles are assigned to universal grammar and language variation is restricted to certain options as to how these principles apply' [9]. The syntax of a natural language as Chomsky Postulated is described in relation to universal principles from which particular languages draw from. The main tenets of this theory is that an individual's syntactic knowledge consists of a finite set of fundamental principles present in all languages and a finite set of variables peculiar to particular languages known as parameters [6]. Within language acquisition this principle postulates that principles are parameters are genetically constructed.

Based on the principles of the universal grammar, Klein \& Marthadjono [10] opined that universal grammar must interact with a learning mechanism to allow convergence of a particular representation required by the target language. The effect of this phenomenon is that when learners acquire an L2 there is a transfer of some of the parameters of L1 to their L2. The interference of these parameters in the L2 makes learners to face difficulty in acquiring the L2.

\section{METHODOLOGY}

The study participants were 50 undergraduates at a Nigerian university. We chose undergraduates because of their exposure to the use of English as a general course of study. It is assumed that these students having been exposed to Standard English from primary school to university level would possess a high level of proficiency. Their average age was 23 (range 19 to 30). Our first test was designed to examine learner's knowledge of quantifiers. We presented two pictures and learners were asked to give an interpretation of the diagrams using quantifiers ' $a$ ' and 'every'. The second step was to present sentences with more than one quantifier. Participants were given enough time to answer their questions. The situation was such that both surface and inverse scope reading was possible. However, only the inverse scope reading was true. Presenting only a surface interpretation was evidence that participants could only access surface scope reading. The third test presented the same set of questions with a context. Respondents were asked to read the short stories and present a new set of answers.

\section{Data 1 \\ Prediction test}

Data 1 was designed to test learner's use of the generalized quantifier within a given context. The research question addressed here is stated below: 
1. Do Nigerian second language learners understand the context where universal quantifiers can be applied?

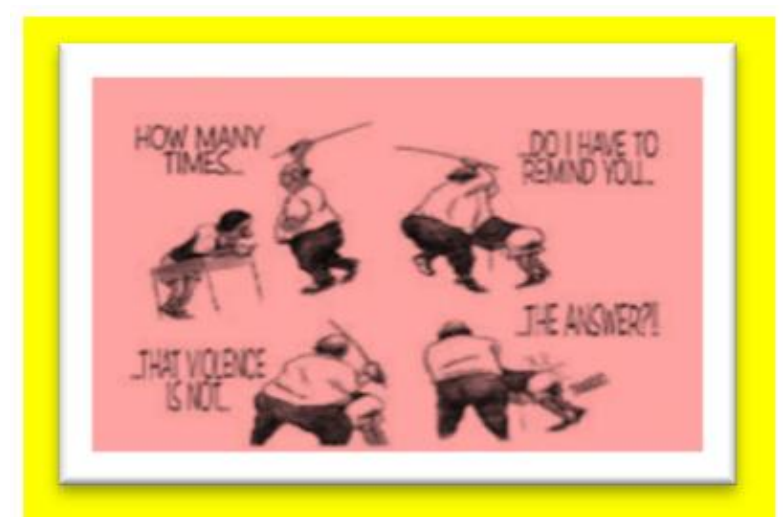

Image A

\section{RESULTS}

a. Every teacher flogged a student.
The test consists of reading two different sets of pictures, a subject oriented picture, and an object oriented picture [12], and providing a contextual answer using 'every' or 'a'. Participants were asked to compare image A to image B before providing their answers.



Image B

Complete interpretation (for every student there was a teacher who flogged them)

Restricted interpretation (a teachers flogged all the students)

Table-1: Mean percentage of participants' response on research question 1

\begin{tabular}{|c|c|c|c|}
\hline No. of complete set interpretation & $\%$ & No of restricted set interpretation & $(\%)$ \\
\hline 7 & 14 & 43 & 86 \\
\hline
\end{tabular}

Data 2

\section{Interpretive preferences}

The test involved presenting ambiguous statements containing quantifiers such as all, every, each and negative polarity item 'not', the research question answered is stated below:

2. Do Nigerian students have a second interpretation in a given expression with a wide scope reading?

1. The teacher punished the student with a pair of scissors.
2. A preacher stood at every pulpit.

3. There is an award for each participant.

4. Everyone who saw a dog liked it.

5. All the kids did not come to school today.

Students were asked to interpret the sentences above. At first some students had no clue of what was expected; clue was therefore given to show that the response was needed in reference to quantities specified in the expression.

Table-2: Mean percentages of participants' response on research question 2

\begin{tabular}{|l|l|l|l|l|l|l|l|}
\hline & $\begin{array}{l}\text { No. of complete set } \\
\text { interpretation }\end{array}$ & $\boldsymbol{\%}$ & $\begin{array}{l}\text { No. of restricted set } \\
\text { interpretation }\end{array}$ & $\boldsymbol{\%}$ & $\begin{array}{l}\text { Other } \\
\text { interpretations }\end{array}$ & \%otal & $\begin{array}{l}\text { Total } \\
\text { \% }\end{array}$ \\
\hline 1 & 3 & 6 & 40 & 80 & 7 & 14 & 100 \\
\hline 2 & 2 & 4 & 30 & 60 & 18 & 36 & 100 \\
\hline 3 & 7 & 14 & 39 & 78 & 4 & 8 & 100 \\
\hline 4 & 16 & 32 & 34 & 68 & - & - & 100 \\
\hline 5 & 5 & 10 & 45 & 90 & - & - & 100 \\
\hline
\end{tabular}

For each quantifier expression that was presented, the percentage of the three possible responses was calculated. The rows also contains a possible interpretation considering the different level of understanding of the respondents a. The teacher punished the student with a pair of scissors

Sentence 1 contains an ambiguous statement. In the first interpretation, the scope of the quantifier ' $a$ ' could be read over 'the teacher'. In this case the sentence implies that the teacher had punished the student using a pair of scissors. In a second reading 
where ' $a$ ' is given a restricted (narrow) set interpretation, it could mean that the teacher punished the student who had a pair of scissors. In the results above, $80 \%$ of the respondents preferred a restricted set interpretation of the sentence.

\section{b. A preacher stood at every pulpit}

The sentence above presents the universal quantifier 'every' at the object position. The same procedure was applied to the respondents where they were supposed to present a reading of the sentence. In the first interpretation, if 'every' has a scope reading over the NP at the subject position, this would result in such expression as for every pulpit, there was a different pulpit standing. Only 4\% preferred this response. In a more narrow interpretation, the expression could mean that there was a particular preacher who stood at every pulpit. Results of our test showed that $60 \%$ of the students preferred a restricted set interpretation where the sentence implied that a particular preacher was there at every pulpit. $34 \%$ of the respondents also gave a different interpretation of the sentence which did not relate to the meaning inferred by the quantifier.

\section{c. There is an award for each participant}

In the sentence above, two sets of interpretations are possible. If the quantifier at the subject NP scopes over the object NP, this sentence would mean that each of the participants will receive a particular award. $72 \%$ of the respondents opted for the surface reading. Following an inverse scope interpretation where 'each' has scope over the subject $\mathrm{NP}$, this sentence could mean that each participant will receive a different kind of award. $14 \%$ of the participants chose the inverse scope reading while $8 \%$ presented totally different interpretation. d. Everyone who saw a dog liked it.

In the first instance where the subject NP scopes over the object NP, the interpretation is that everyone who saw a particular dog liked it. A complete set interpretation would imply that everyone who saw a dog anywhere liked it. In the sentence above, $68 \%$ of the respondents preferred a narrow interpretation while $32 \%$ preferfred a full interpretation.

e. All the kids did not come to school today.

The negative polarity item 'not' appears to be the least confusable; when it is presented, there was no different response recorded. It is possible from a restricted reading that the whole school was empty where none of the kids actually came to school. This corresponds to the overt syntactic structure of the sentence. $90 \%$ of the respondents preferred the restricted set interpretation while only $10 \%$ of the respondents believed that not all the kids came to school today.

\section{Data 3 \\ Intensionality Test}

The test involved presenting short stories that could provide a context for the questions posed earlier. This question answers the research question stated below.

3. Does the presence of a context affect the reading of ambiguous scope quantifier expressions?

In the second test, Participants read the ambiguous quantifier sentences earlier presented. This time it was followed by a short story that is a reasonable discourse continuation of the quantifier sentence with an inclusive interpretation.

Table-3: Mean percentage of participants' response on research question 3

\begin{tabular}{|l|l|l|l|l|l|l|l|}
\hline & $\begin{array}{l}\text { No. of complete } \\
\text { set interpretation }\end{array}$ & $\%$ & $\begin{array}{l}\text { No. of restricted } \\
\text { set interpretation }\end{array}$ & $\%$ & $\begin{array}{l}\text { Other } \\
\text { interpretations }\end{array}$ & $\%$ & $\begin{array}{l}\text { Total } \\
\%\end{array}$ \\
\hline 1 & 42 & 84 & 5 & 10 & 3 & 6 & 100 \\
\hline 2 & 46 & 92 & 3 & 6 & 1 & 2 & 100 \\
\hline 3 & 27 & 56 & 23 & 46 & - & - & 100 \\
\hline 4 & 23 & 46 & 23 & 46 & - & - & 100 \\
\hline 5 & 37 & 74 & 13 & 26 & - & - & 100 \\
\hline
\end{tabular}

The responses were analysed using the same procedure in data 1 . The presence of a stimulus resulted in changes to responses made earlier by participants. The short stories presented were in favour of a complete set interpretation. In Q1, although few participants stuck to their earlier interpretations, others preferred a complete interpretation given a new context. There was an increase from $14 \%$ to $84 \%$ for the complete set interpretation while other forms of interpretation also reduced from $14 \%$ to $6 \%$.

In Q2, the number of restricted set interpretation declined from $60 \%$ to $6 \%$. The presence of a context helped to provide other meanings that can be inferred from the sentence contrary to result in the first data. Other interpretations also declined from $36 \%$ to $2 \%$. This significant difference also shows the role of a stimulus in enhancing comprehension. Q3 and Q4 showed the same results of $56 \%$ response. The distributive quantifiers 'each' and 'every' despite the presence of a context still pose a problem for participants. The absence of other interpretations was recorded. The presence of a context favoured the not> all response for QNP> neg. Contrary to $10 \%$ complete set interpretation recorded in Table-1, the inverse scope reading was preferred in Table-3. 


\section{DISCUSSION}

This study was concerned with the interpretation of scope ambiguous sentences and expressions that contain negation and a quantified NP as the subject. In the first study, students produced more of a restricted (narrow) scope interpretation for Q1- Q5. The overall frequency of the target sentence (complete set interpretation) was low. Results of the production confirmed that L2 users do not possess a second interpretation for ambiguous quantifier expressions. The presence of other interpretations even after a context shows that some students possess a low level of comprehension in disambiguating quantifier expressions. From our study, certain factors can affect the scope interpretation of ambiguous quantifier expressions by L2 learners.

\section{Overt Syntactic Structure}

In the first task, the respondents showed a restricted scope reading for the sentences without context. The analysis of the data with negation and quantifier NP as subject also showed that Nigerian students make a preference of narrow interpretation. This is because the syntactic structure of the negative quantifier expression favours a narrow scope reading. This could be as a result of the sentence structure. This is partly consistent with Musolino's findings on the observation of isomorphism where children made a preference for simpler syntactic structure. In interpreting quantifier expressions, individuals prefer interpretations with the least processing difficulty $[7,8]$.

For expression with negation within acontextual situation, $90 \%$ of the participants chose a surface scope reading. This is consistent with earlier claims that individuals prefer a surface scope interpretation for quantifier NP with negation [12]. Another reason for this response is that L2 learners are often exposed to syntactic structures where the negation usually takes scope over the constituents and surface ccommand relations.

\section{Influence of $\mathbf{L 1}$}

The findings on the influence of $\mathrm{L} 1$ revealed that learners make a scope preference for restricted set interpretation as illustrated in table 4.1. The cost of assigning a complete set interpretation for second language users as the table shows is high. This also predicts that the cost of processing a complete set interpretation for L2 learners is difficult. This shows that learners' interpretation is constrained by the parameters that govern their L1. A comparison between the closed and open test shows the influence of L1 transfer on interpretation. This phenomenon emanates from the absence of such structural ambiguity in their L1. In order to clarify this fact, some participants were asked to give a verbal interpretation of the sentences in their L1. The choice of interpretation in the L1 also showed a preference for narrow scope reading.
For quantifier noun phrase with negation, participants opted for the all $>$ not interpretation as this is the most accessible response processed in the L1. The result of our finding is consistent with other studies in this area $[13,14]$ which show that the presence of the L1 can affect information processing in the L2. The result of the second test also served as evidence of the role of L1 transfer. Despite the presence of a stimulus, some participants still preferred a restricted set interpretation for contexts where the complete set interpretation was true. Mental representations of L1 learners are usually different from those of L2. This also accounts for the inability of some participants to understand the tests given even with the presence of a context.

\section{The role of input}

Input is necessary in correcting learner's interpretation. With the presence of a stimulus, participants reverted to a complete set interpretation. This agrees with Scwartz \& Sprouse' [15] full access transfer hypothesis which suggest that parameter reset is possible. Reports from previous findings show that the presence of an input is necessary to provide truth value in contexts where the overt syntactic structure might seem correct [16]. Studies have shown that L1 and L2 parameters fluctuate until proper input is provided for learners. This is because second language learners' interpretations are consistent with the frequency of input. When learners are exposed to a wide variety of L2 there is a tendency to expand the vocabulary and semantic components. Contextual information served as input for participants to provide a complete set interpretation as found in Table-3. It also helped to eliminate the possibility of other interpretations as found in a contextual situation in Table-1. The presence of the right input will serve to reset the parameters and processing memory of the L1. Input is therefore necessary in the disambiguation of quantifier scope expressions.

\section{CONCLUSION AND RECOMMENDATION}

As summarized above, this research addressed scopal interpretation of quantified expressions by L2 learners. It focused on such quantifiers as: each, every, a, all and negation. Our study showed that some language learners cannot provide a second interpretation of quantifier ambiguous expressions since their linguistic knowledge is restricted to surface reading. The study also revealed that the absence of some of the English quantifiers in the L1 affect comprehension of quantified expressions. These findings may contribute to a new approach to second language acquisition in the area of interpreting ambiguous quantifier expressions, by helping language scholars to explore different ways of addressing ambiguity challenges faced by learners. This study therefore suggests that:

- Proper attention should be given to the study of quantifiers. Some of the participants could 
not identify quantifier expressions because some English quantifiers have no equivalent in the L1. Poor understanding of the concept would result in difficulty in its disambiguation. A proper understanding of English quantifiers will aid in disambiguation of quantifier expressions.

- Language instructors should provide input that will assist learners in expanding their knowledge of quantifier expressions. Learners show a preference for a complete interpretation with a given context, this is an evidence that parameter reset is possible. Hence the right input can assist in correcting a restricted set interpretation of scopally ambiguous expressions.

- Poor comprehension can also stem from poor instruction in second language acquisition. Learners should be properly instructed in responding to quantifier ambiguous expressions.

- More studies in this area should be carried out in relation to individual quantifiers rather than expressions. This will help to improve the linguistic system of language learners.

- Further studies should be carried out to ascertain the role of L1 in disambiguation of scopally ambiguous quantified expressions.

\section{REFERENCES}

1. Burg J. Quantifier (linguistics). 2014. Retrieved from on 01-12-14 http://en.m.wikipedia.org

2. Kwak, O'Grady W. Language acquisition without an acquisition device. Language Teaching. 2012 Jan;45(1):116-30.

3. Gutierrez-Rexach J. Quantification. In Hualde J, Olarrea A, Olaruke E (Eds), The handbooks of Hispanic linguistics. (202-302). Malden: WileyBlackwell. 2012.

4. Saeed A. Media, racism and Islamophobia: The representation of Islam and Muslims in the media. Sociology Compass. 2007 Nov;1(2):443-62.

5. May R. The grammar of quantification. $\mathrm{PhD}$ Dissertation. Massachusetts: University of Massachusetts. 1977.
6. Simoiu A. The split IP parameter in second language learning. Newcastle: Cambridge Scholars Publishing. 2014

7. Kurtzman H, MacDonald M. Resolution of quantifier scope ambiguities. Cognition, 1993;48:243-279.

8. O'grady W. Syntactic carpentry: an emergentist approach to syntax. Erlbaum: Mahwah. 2005.

9. Chomsky N. The minimalist program. Massachusetts: MIT Press. 2014.

10. Klein E, Martohadjono. Investigating second language grammars: Some conceptual and methodological issues in generative SLA research. (Eds). The development of second language grammars: A generative approach. 3-36 Amsterdam: John Benjamin Publishing. 1999.

11. Musolino A, Naldi N, Bortesi B, Pezzuolo D, Capelletti M, Missale G, Laccabue D, Zerbini A, Camisa R, Bisagni G, Neri TM. Immunoglobulin $\mathrm{G}$ fragment $\mathrm{C}$ receptor polymorphisms and clinical efficacy of trastuzumab-based therapy in patients with HER-2/neu-positive metastatic breast cancer. Journal of Clinical Oncology. 2008 Apr 10;26(11):1789-96.

12. Horn L. A natural history of negation. Chicago: University Press. 1989.

13. Musolino J. Universal grammar and the acquisition of semantic knowledge. PhD Dissertation. Maryland: University of Maryland. 1998.

14. Assadollahfan H, Lofti A. Quantification scope ambiguity resolution: evidence from Persia and English. English language Teaching, Canadian Centre of Science Education, 2010;3(3):150-161.

15. Scwatz B, Sprout R. Second language cognitive states and the full transfer/full access model. Second Language Research, 1996;12:40-72.

16. Ozcelik O. L2 acquisition of scope: testing the full transfer full access hypothesis. In Bowell M, Ionin T, Montul S, Treblay A. (Eds), Proceedings of the $10^{\text {th }}$ Generative approaches to SLA conference (GASLA). Pp. 168-179. Somerville: Cascadilla Proceeding Project. 2009. 